\title{
Effects of Induction Heat Bending and Heat Treatment on the Boric Acid Corrosion of Low Alloy Steel Pipe for Nuclear Power Plants
}

\author{
Ki-Tae Kim', Min-Chul Shin ${ }^{3}$, Hyun-Young Chang ${ }^{2}$, Heung-Bae Park ${ }^{2}$, Gi-Ho Sung ${ }^{3}$, and Young-Sik Kim ${ }^{1, *}$ \\ ${ }^{1}$ Materials Research Center for Clean and Energy Technology, School of Materials Science and Engineering, Andong \\ National University, Gyeongbuk 36729, Republic of Korea \\ ${ }^{2}$ Power Engineering Research Institute, KEPCO E\&C, Gyeongbuk 39660, Republic of Korea \\ ${ }^{3}$ Sungil SIM Co. Ltd, Busan 46753, Republic of Korea
}

\begin{abstract}
In many plants, including nuclear power plants, pipelines are composed of numerous fittings such as elbows. When plants use these fittings, welding points need to be increased, and the number of inspections also then increases. As an alternative to welding, the pipe bending process forms bent pipe by applying strain at low or high temperatures. This work investigates how heat treatment affects on the boric acid corrosion of ASME SA335 Gr. P22 caused by the induction heat bending process. Microstructure analysis and immersion corrosion tests were performed. It was shown that every area of the induction heat bent pipe exhibited a high corrosion rate in the boric acid corrosion test. This behavior was due to the enrichment of phosphorous in the ferrite phase, which occurred during the induction heat bending process. This caused the ferrite phase to act as a corrosion initiation site. However, when re-heat treatment was applied after the bending process, it enhanced corrosion resistance. It was proved that this resistance was closely related to the degree of the phosphorus segregation in the ferrite phase.
\end{abstract}

(Received October 19, 2015; Accepted May 19, 2016)

Keywords: low alloy steel, induction heat bending, boric acid corrosion, phosphorus

\section{INTRODUCTION}

In industries such as chemical plants, power plants, and shipbuilding, the temperature and flow pressure in pipes is very high, and bent pipes have gradually come into use in order to mitigate thermal expansion and shock resulting from these industrial processes [1-3]. This process of bending pipes typically involves methods of transforming a straight pipe into bent forms, and generally these methods can be classified as cold or hot bending, depending upon the bending temperature [4].

Typically, when a traditional bending process is applied, the degree of bending is limited, because the thickness of the extrados area of the pipe may be abnormally reduced by the bending radius. However, with the induction heat bending method, average compressive stress can be applied to the bent strain areas during the process. Application of average compressive stress can minimize the reduction in thickness that occurs during conventional bending process, and this is

* Corresponding Author: Young-Sik Kim

[Tel: +82-54-820-5504, E-mail: yikim@anu.ac.kr]

Copyright (c) The Korean Institute of Metals and Materials an advantage of the induction heat bending method over traditional bending processes. In addition, it is well known that the induction heat bending process can produce high quality bent pipes using automatic controls [5]. Analyses and process designs to optimize the bending process have also been studied [6-15]. As a result, international standards for induction bends have been established [16].

When the induction heat bending process is applied to low alloy steel, microstructural changes may arise because of the thermo-mechanical process. In low alloy steel, the steel shows an austenitic structure at high temperature, and upon cooling, the primary ferrite begins to precipitate at the austenite grain boundaries, and then the ferrite phase gradually increases with the decreasing temperature. After the steel has been heated to austenite, the austenite is transformed into primary ferrite and pearlite upon cooling [17].

In a real heat treatment process, phase transformation takes place through a wider range of temperature than during iso-thermal transformation, because of continuous cooling. That is, the final microstructure can be determined by the phase transformations during the thermo-mechanical process [18], and thus microstructural change may arise that causes a 
Table 1. Chemical composition of ASME SA335 Gr. P22 low alloy steel (wt \%)

\begin{tabular}{ccccccccc}
\hline $\mathrm{C}$ & $\mathrm{Mn}$ & $\mathrm{P}$ & $\mathrm{S}$ & $\mathrm{Si}$ & $\mathrm{Cr}$ & $\mathrm{Mo}$ & $\mathrm{Fe}$ & Remarks \\
\hline 0.1 & 0.46 & 0.01 & 0.004 & 0.34 & 2.24 & 0.9 & bal. & \\
\hline
\end{tabular}

degradation of the properties of the steel [19]. Also, a previous study determined that equal channel angular pressing elongated the ferrite and pearlite grains and spheroidal cementite was observed [20]. By increasing the heat treatment cycles, the microstructure was changed from pearlite to grain boundary cementite [21]. It has sometimes been reported that the cracks have formed at inclusion sites due to the bending stresses, and formed over-stress resulting from sudden thermal expansion during the induction heating process [22].

Many carbon steels and low alloy steels have been applied and used for various high temperature service applications, including feed-water systems in pressurized water reactors. Under such conditions, these materials frequently exhibit degraded properties, including low cycle corrosion fatigue [23], pitting corrosion [24], intergranular cracking and flow assisted corrosion [25]. Boric acid corrosion is one of the serious types of corrosion damages found in the primary systems of most nuclear power plants [26,27]. As a consequence, regulatory authorities have been interested in boric acid corrosion as one of the important mechanisms of pipe materials. Boric acid corrosion is a form of uniform corrosion caused by boric acid in water. In general, boric acid in the water can induce corrosion at the metal surface. Boric acid is mildly acidic, compared with hydrochloric or nitric acids, however, even a small amount of boric acid may generate an increase in proton ions and lower $\mathrm{pH}$, and thus increase the corrosion rate. In a corrosion process, an oxidation reaction occurs at the anodic areas, and a reduction reaction at the cathodic areas, and thus the metal surface uniformly corrodes.

Induction bending involves a thermo-mechanical process at high temperature, and thus the ferrite and pearlite phases in the alloys may transform. Cementite acting as a cathode can galvanically corrode the ferrite. Also, the pearlite corrodes at a comparatively low rate because of the relatively massive
Table 2. Identification symbols for test areas of ASME SA335 P22 low alloy steel bent pipe
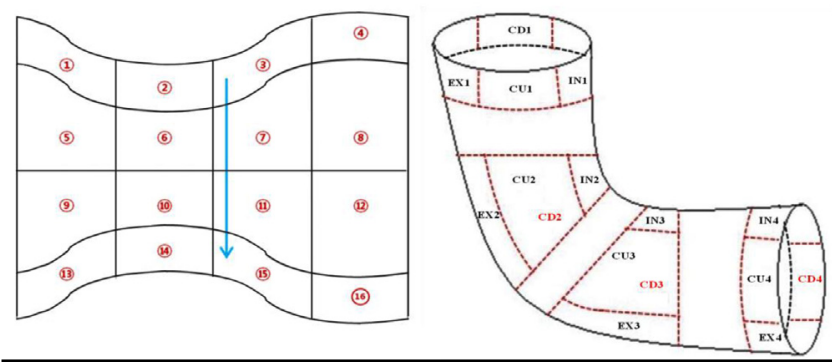

\begin{tabular}{cccccc}
\hline Areas & $\begin{array}{c}\text { Base } \\
\text { Metal }\end{array}$ & Intrados & Crown Up & $\begin{array}{c}\text { Crown } \\
\text { Down }\end{array}$ & Extrados \\
\hline $\begin{array}{c}\text { No bent } \\
\text { region }\end{array}$ & BM-M & - & - & - & - \\
\hline $\begin{array}{c}\text { Transition } \\
\text { region in } \\
\text { bent }\end{array}$ & - & IN-T & CU-T & CD-T & EX-T \\
\hline
\end{tabular}

form of cementite formed by the decomposition of austenite. The corrosion rate increases as the sizes of the iron carbide particles decrease. The rate is cathodically controlled and hence depends on hydrogen overvoltage and the interfacial area of the cathodic sites [28]. Among alloying elements, both sulfur and phosphorus markedly increase the rate of attack of acids. These elements form compounds that apparently have low hydrogen overvoltage. In addition, they tend to decrease anodic polarization so that the corrosion rate of iron is stimulated by these elements at both anodic and cathodic sites $[28,29]$. However, there has been little study on the effect of the bending process of pipes on the corrosion and microstructure of low alloy steels.

This work focused on the effect of the bending process and heat treatment on the boric acid corrosion of induction heat bent pipes, using microstructure analysis and corrosion tests.

\section{MATERIAL AND METHODS}

The test material in this work was SA335 Gr. P22 low alloy steel (10in. S.120, R=410 mm) made by ASME specification [30]. Straight pipe was bent using a high frequency induction heat bending machine (Model; HFB-9N), and the bending angle was $45^{\circ}$. During the bending process, real bending temperatures for each of the intrados, extrados, and crown down areas were measured, and the maximum 

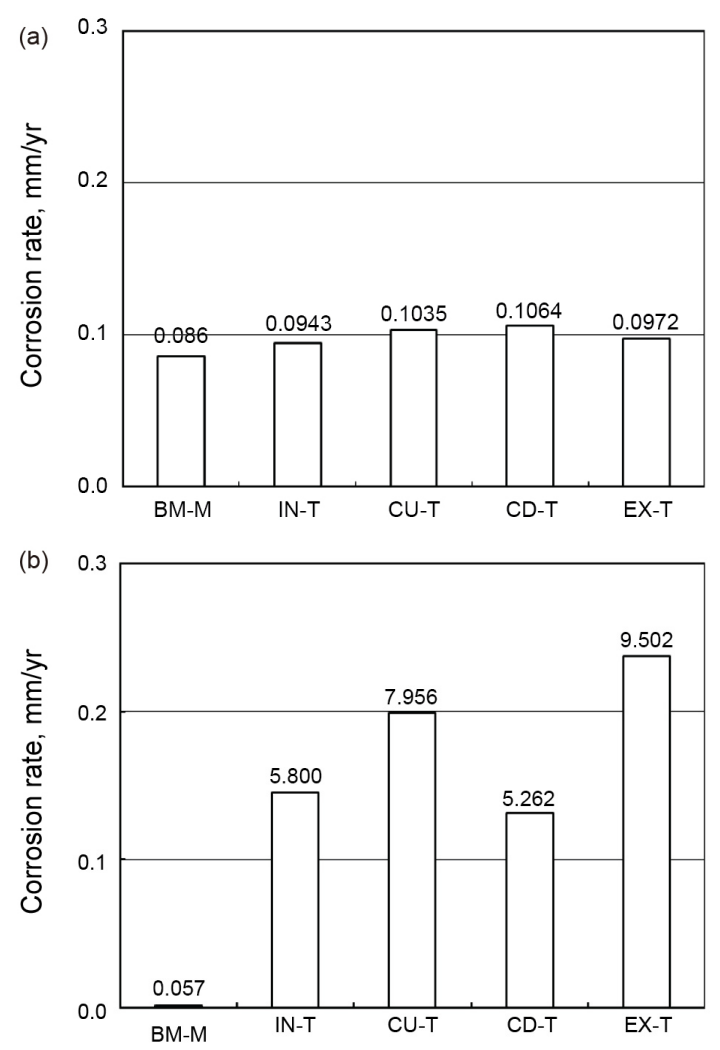

Fig. 1. Corrosion rate of base metal and bent areas of ASME SA335 P22 low alloy steel pipe by immersion test for 100 hours; (a) aerated $11,400 \mathrm{ppm}$ boric acid at $40{ }^{\circ} \mathrm{C}$, (b) deaerated 5,700 ppm boric acid at $200{ }^{\circ} \mathrm{C}$

temperature was $1,130{ }^{\circ} \mathrm{C}$ on the intrados area, $1,060{ }^{\circ} \mathrm{C}$ on the extrados area, and $1,034{ }^{\circ} \mathrm{C}$ on the crown down area. The pipe was locally heated by heating coil, and then forced-air cooled. Table 1 shows the chemical composition of the experimental alloy. Table 2 represents the bent regions and identification symbols; base metal (BM) and intrados area (IN), crown-up area (CU), crown-down area (CD), and extrados area (EX). Also, IN-T means the intrados area of the transition region and EX-T indicates the extrados area of the transition region, and so on.

The specimens were tested as-bent and then re-heat treated (The re-heat treatment process included solution heat treatment at $900{ }^{\circ} \mathrm{C}$ for 1 hour, and then air cooling (AC) or water quenching (WQ). Another method was a solution heat treatment at $900{ }^{\circ} \mathrm{C}$ for 1 hour, and then air cooling to $600{ }^{\circ} \mathrm{C}$, and after maintenance for 1 hour at $600{ }^{\circ} \mathrm{C}$, air cooling to room temperature.).
The microstructure was observed using an optical microscope (ZEISS AXIOTECH 100HD) and SEM-EDS (Tescan, VEGA II LMU), after etching by 3\% nital (97 ml Alcohol $+3 \mathrm{ml} \mathrm{HNO}_{3}$ ).

The corrosion rate in boric acid solution was determined using an autoclave (Hastelloy C276). Before heating to test temperature, the test solution was de-aerated using $\mathrm{H}_{2}$ gas at the rate of $300 \mathrm{cc} / \mathrm{min}$. for 100 hours. The test temperatures were $40{ }^{\circ} \mathrm{C}$ for $11,400 \mathrm{ppm}$ boric acid and $200{ }^{\circ} \mathrm{C}$ for 5,700 ppm as boric acid [12,13].

\section{RESULTS}

Boric acid corrosion can occur in the primary system of a nuclear power plant. The corrosion rate in boric acid solution was measured according to EPRI report [26], and is shown in Figure 1. Figure 1 shows the corrosion rates of the base metal and bent regions of ASME SA335 P22 low alloy steel pipe, after 100 hours immersion in boric acid. Figure 1 (a) shows the corrosion rate determined in aerated 11,400 ppm boric acid at $40{ }^{\circ} \mathrm{C}$. The corrosion rate of the base metal (BM-M) showed $0.086 \mathrm{~mm} / \mathrm{y}$, and the intrados (IN-T), crown-up (CU-T), crown-down (CD-T), and extrados areas (EX-T) in the transition region of bent specimen showed 0.094, 0.104, 0.106 , and $0.097 \mathrm{~mm} / \mathrm{y}$, respectively. The corrosion rate of the bent specimen is similar to that of the base metal in the low temperature test condition.

However, in Figure 1 (b), which represents the corrosion rate in de-aerated $5,700 \mathrm{ppm}$ boric acid at $200{ }^{\circ} \mathrm{C}$, the corrosion rate of the base metal (BM-M) showed $0.057 \mathrm{~mm} / \mathrm{y}$ and intrados (IN-T), crown-up (CU-T), crown-down (CD-T), and extrados areas (EX-T) in the transition region of the bent specimen showed 5.800, 7.956, 5.262, and $9.502 \mathrm{~mm} / \mathrm{y}$ respectively. The corrosion rate of the bent specimen was determined as ca. 100 times higher than that of the base metal in the high temperature test condition.

When the test conditions were changed, including de-aeration and temperature, the observed corrosion behavior in the boric acid solution was quite different. Although the change of test conditions did not affect the corrosion rate of the base metal, in the case of the bent region of pipe, the high 

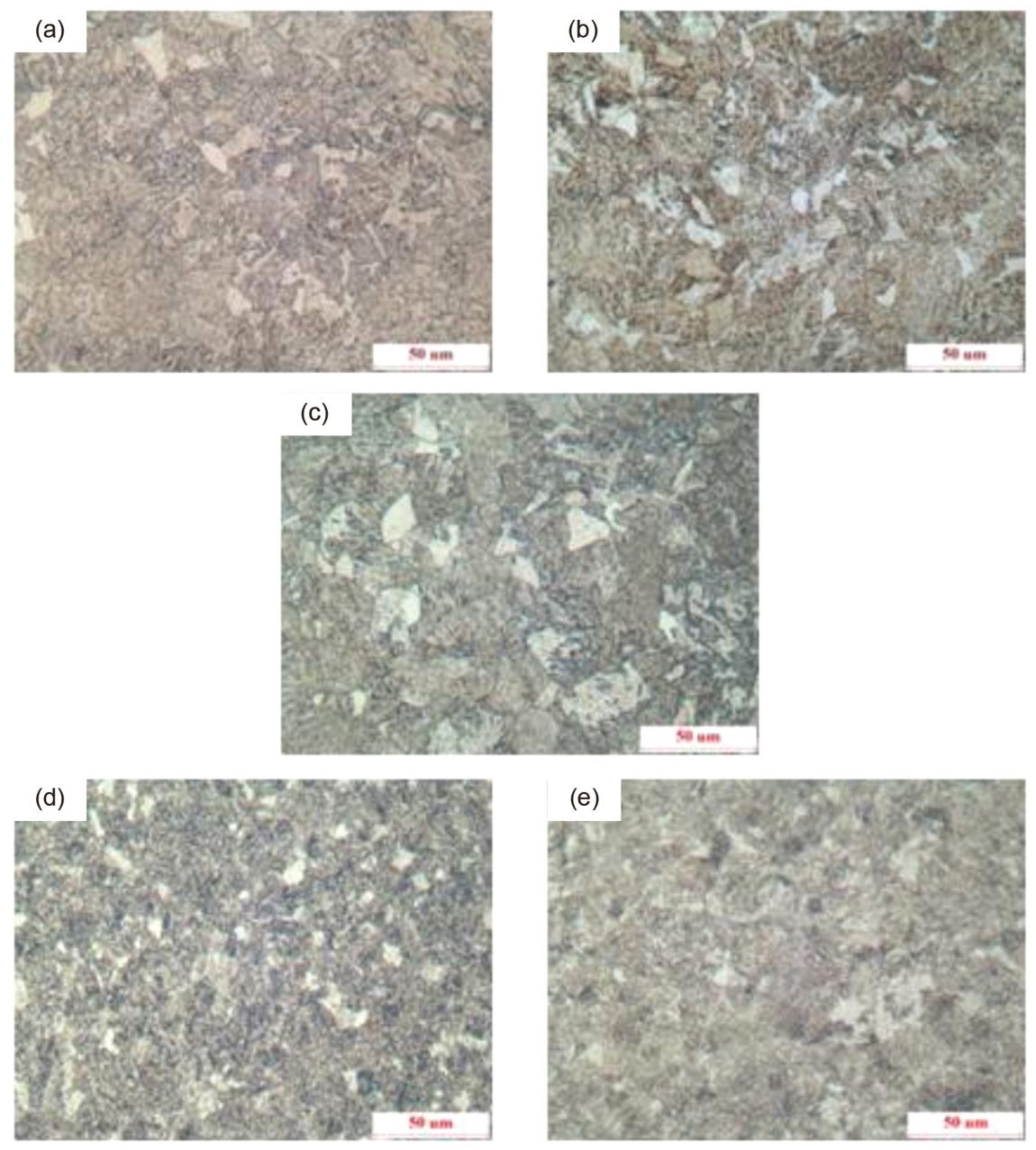

Fig. 2. Optical microstructures of base metal and bent areas of ASME SA335 P22 low alloy steel (Magnification : x200) ; (a) CU-T, (b) CD-T, (C) BM-M, (d) IN-T, (e) EX-T

temperature and high pressure of the solutions greatly increased the corrosion rate.

Figure 2 shows the optical microstructure of the base metal and bent specimen of ASME SA335 P22 low alloy steel (magnification : $\mathrm{x} 200$ ). (a) depicts the CU-T area, (b) is the CD-T, (c) is the base metal, (d) is the IN-T area, and (e) is the EX-T area. In the figures, the white colored area is the ferrite phase, and the dark area is the pearlite phase. Ferrite contents were calculated using an image analyzer with an optical microscope. Ferrite content of the base metal was $17.6 \%$. The ferrite content of the crown up and down was 19.1 and $15.4 \%$, respectively, and those of intrados and extrados were 11.1 and $11.9 \%$, respectively. In spite of the forced-air cooling during the heat bending process, the effect of the cooling was apparently different at the crown up/down and intrados/extrados. The ferrite contents of the crown up and down were a little higher than those of the intrados and extrados, and this behavior seems to be related to the difference in cooling rate.

As described above, the corrosion rate in boric acid solution of every bent region was higher than that of the base metal. If the degradation of properties was induced by the bending process, the mechanism was not clear, based on the optical microstructure. Therefore, after the boric acid corrosion test, the surface of the alloy was observed. Figure 3 shows optical micrographs of the surface after the boric acid test of SA335 P22 low alloy steel (magnification : x200). As shown in the figures, the corrosion occurred selectively in the ferrite phases.

Figure 4 represents the phosphorus contents of the as-bent 

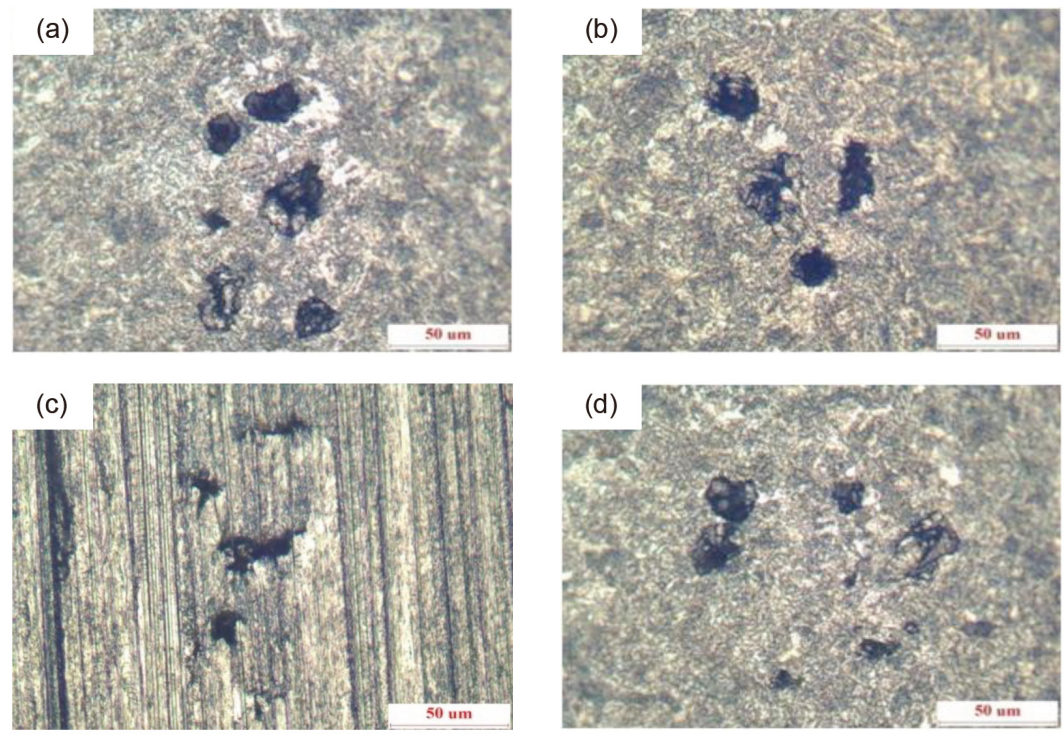

Fig. 3. Optical micrographs on the surface of SA335 P22 low alloy steel after immersion test in $5700 \mathrm{ppm}$ boric acid at $200{ }^{\circ} \mathrm{C}$ (Magnification: x200); (a) IN-T, (b) CU-T, (c) CD-T, (d) EX-T

specimen determined by EDS analysis. (a) is for the pearlite phase, and (b) is for the ferrite phase. A point analysis for $\mathrm{Fe}$, $\mathrm{Cr}$, Mo, Mn, Si, P, and S was performed in each phase, but
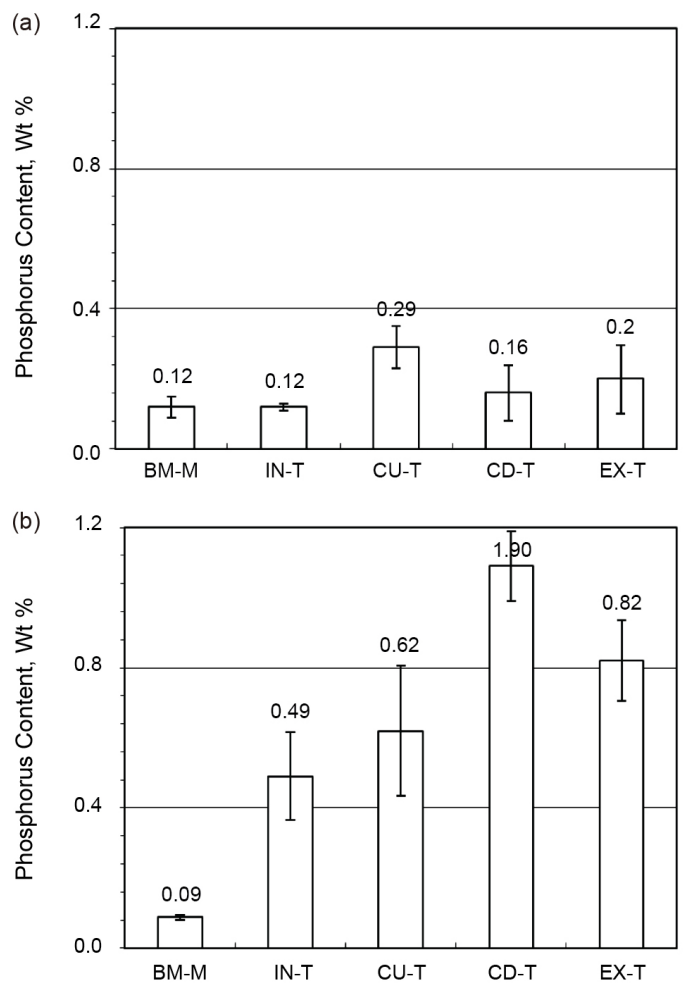

Fig. 4. Phosphorus contents of as-bent specimen by EDS analysis; (a) pearlite phase, (b) ferrite phase they exhibited almost the same content beside the phosphorus. In the base metal, both the pearlite and ferrite phases showed low concentration. However, in the bent regions, while the phosphorus contents in the pearlite phases were low, those in the ferrite phases were very high.

\section{DISCUSSION}

As described above, induction heat bending was performed using a thermo-mechanical process at high temperature and with air cooling. As shown in Figure 4, the phosphorus segregated mainly in the ferrite phases and these phases were selectively corroded, as shown in Figure 3. In order to address this problem, a re-heat treatment was performed after the bending process. The re-heat treatment included solution heat treatment at $900{ }^{\circ} \mathrm{C}$ for 1 hour, and then air cooling (AC) or water quenching (WQ). Another method used was a solution heat treatment at $900{ }^{\circ} \mathrm{C}$ for 1 hour, and then air cooling to $600{ }^{\circ} \mathrm{C}$, and after maintenance for 1 hour at $600{ }^{\circ} \mathrm{C}$, air cooling to room temperature.

Figure 5 shows the corrosion rates for the base metal and bent regions of ASME SA335 P22 low alloy steel pipe after the re-heat treatment. The test condition was de-aerated 5,700 ppm boric acid at $200{ }^{\circ} \mathrm{C}$ for 100 hours, the same as in Figure 


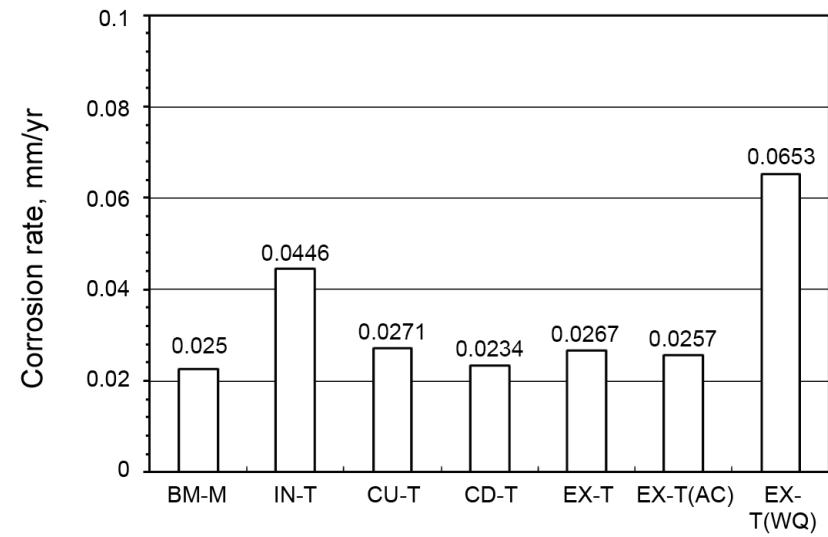

Fig. 5. Corrosion rate for base metal and bent areas of ASME SA335 P22 low alloy steel pipe after re-heat treatment by immersion test for 100 hours in de-aerated 5,700 ppm boric acid at $200^{\circ} \mathrm{C}$

1 (b). In the case of the as-bent specimen, every area showed a high corrosion rate of over $5 \mathrm{~mm} / \mathrm{y}$; but as shown in Figure 5 , re-heat treated specimen exhibited a very low corrosion rate, similar to that of the base metal.

Figure 6 presents the phosphorus contents of the re-heat treated specimen obtained by EDS analysis, where (a) is for pearlite phase, and (b) is for ferrite phase. Point analysis for $\mathrm{Fe}, \mathrm{Cr}, \mathrm{Mo}, \mathrm{Mn}, \mathrm{Si}, \mathrm{P}$, and $\mathrm{S}$ in each phase was performed, and there was almost the same content for the pearlite and the ferrite phases. In particular, the phosphorus contents in both the pearlite and the ferrite phases, as seen in Figure 6, were very low, unlike the results shown in Figure 4.

Microstructure is one of the important factors that influence the grain boundary segregation of phosphorus in low alloy steels [31-33]. Phosphorus segregation in the as-tempered microstructure was found to be faster than in the as-quenched sample [34]. In amorphous alloys, the phosphorous may increase corrosion resistance [35], but the addition of phosphorus in steels increases the cathodic hydrogen evolution reaction and therefore it has a deleterious effect on the corrosion resistance of carbon steels [36].

Consequently, since the induction heat bending process operates by moving a narrow heating band, it is likely that the phosphorus in the alloys diffuses during the bending process and is enriched in the ferrite phase which it's high solubility. Accordingly, it is concluded that the high phosphorus content
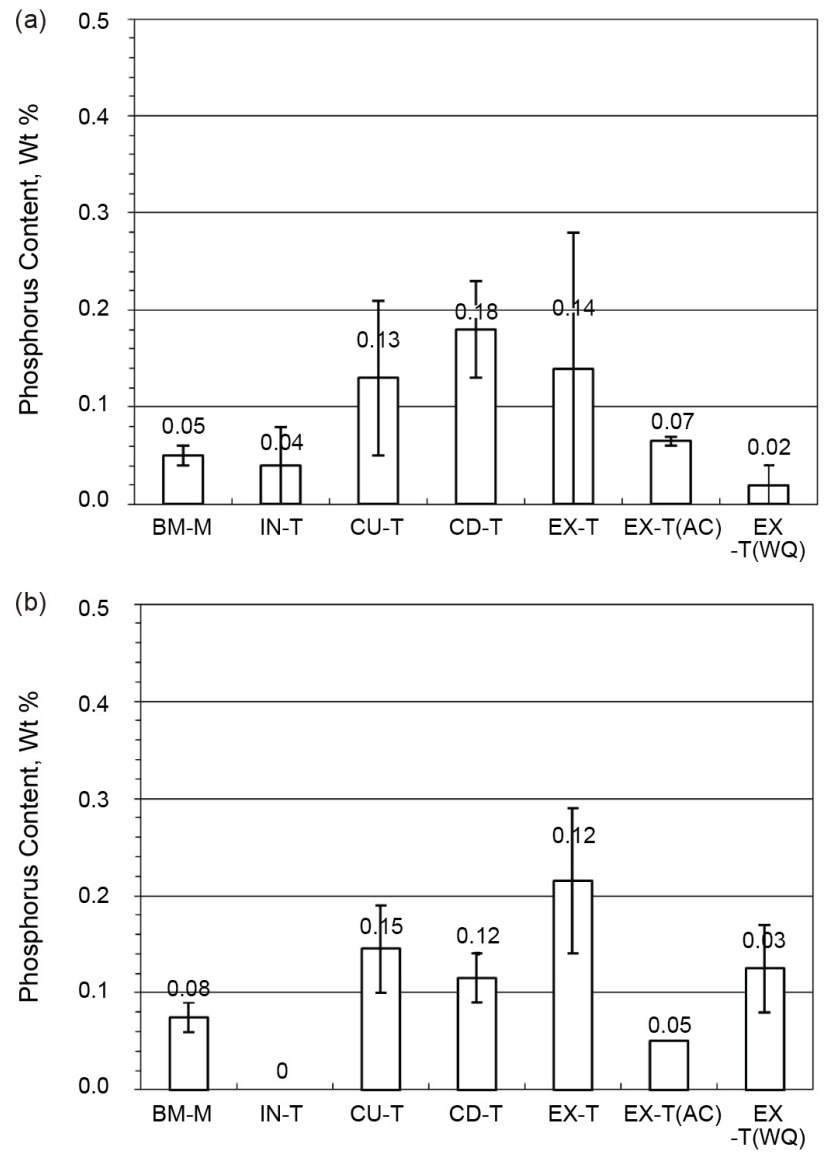

Fig. 6. Phosphorus contents of re-heat treated specimen by EDS analysis; (a) pearlite phase, (b) ferrite phase

in the ferrite phase may induce the boric acid corrosion of bent pipe. Among alloying elements, both sulfur and phosphorus markedly increase a rate of attack in acids. These elements form compounds that apparently have low hydrogen overvoltage. In addition, they tend to decrease anodic polarization so that the corrosion rate of iron is stimulated by these elements at both anodic and cathodic sites [28,29].

Figure 7 shows the optical microstructures of the bent regions of ASME SA335 P22 low alloy steel after re-heat treatment (magnification: x200). As shown in the figure, re-heat treatment by annealing at $900{ }^{\circ} \mathrm{C}-1$ hour-AC, and then $600{ }^{\circ} \mathrm{C}-1$ hour-AC induced a change in the microstructure, from heterogeneous to homogeneous, and increased the ferrite phase area, due to the recrystallization and grain growth induced by the heat treatment. Ferrite contents were calculated using an image analyzer and optical microscope. 

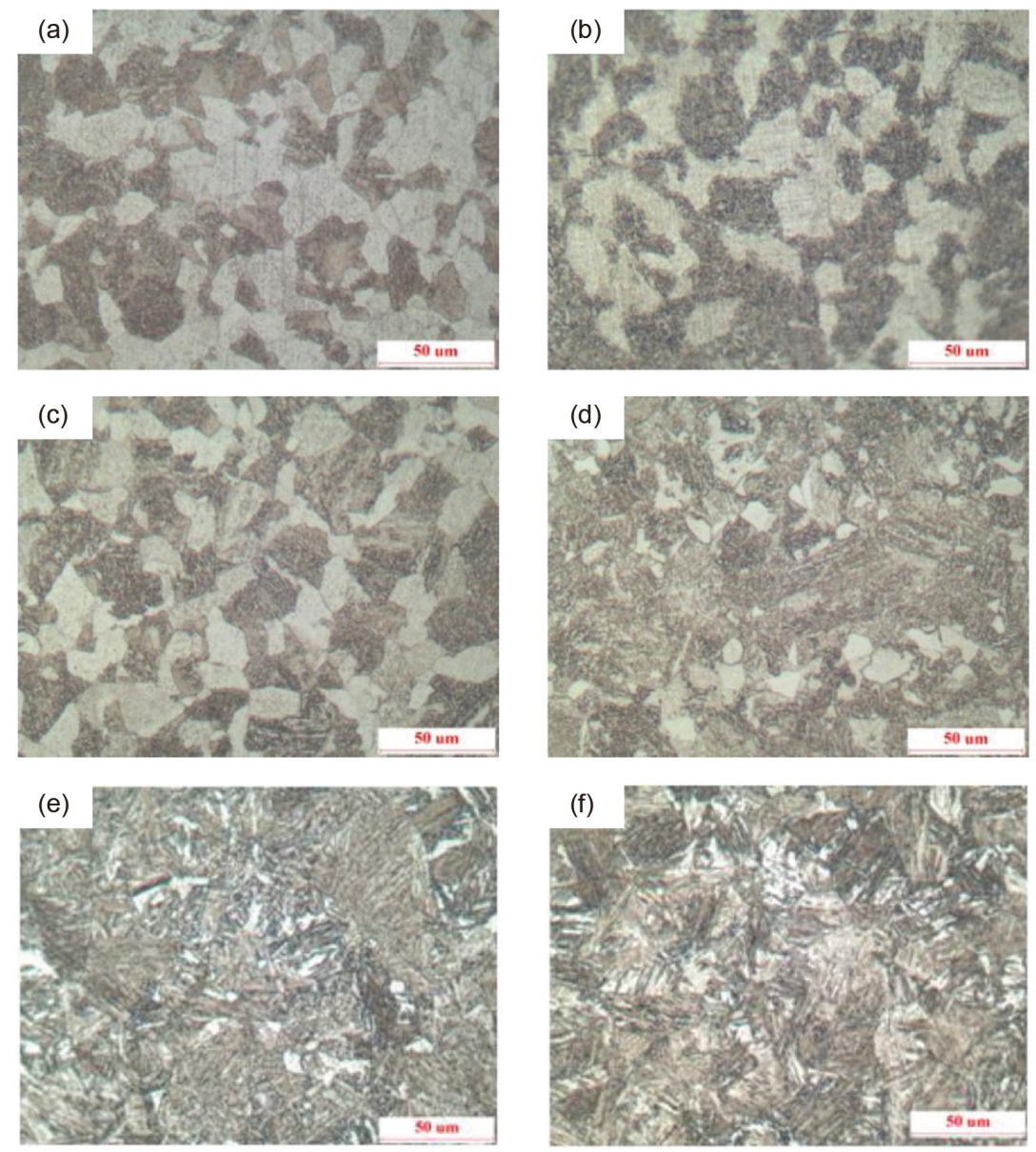

Fig. 7. Optical microstructures on bent areas of ASME SA335 P22 low alloy steel after re-heat treatment (Magnification: x200); (a) CU-T, (b) CD-T, (c) IN-T, (d)(e)(f) EX-T (a, b, c, d : $900{ }^{\circ} \mathrm{C}-1$ hour-AC $\rightarrow 600{ }^{\circ} \mathrm{C}-1$ hour-AC, e : $900{ }^{\circ} \mathrm{C}-1$ hour-AC, f : $900{ }^{\circ} \mathrm{C}-1$ hour-WQ)

Following re-heat treatment, the ferrite contents of the crown up and down were founded to be 56.7 and $41.4 \%$ and those of intrados and extrados were 51.6 and $19.7 \%$, respectively. The ferrite contents of each area increased more than those of the as-bent specimen. These increases were due to the phase transformation at high temperature. However, annealing at $900{ }^{\circ} \mathrm{C}-1$ hour-AC and annealing at $900{ }^{\circ} \mathrm{C}-1$ hour-WQ are not recommended, because they result in martensite transformation.

Figure 8 shows the relationship between the phosphorus content of the ferrite phase and the corrosion rate in deaerated $5,700 \mathrm{ppm}$ boric acid at $200{ }^{\circ} \mathrm{C}$. In the case of the as-bent pipe (०), the phosphorus content in the ferrite phase was high, and its corrosion rate was very fast. However, in the case of re-heat treated pipe $(\bullet)$, the level of phosphorus in the ferrite phase was low, and the corrosion rate was greatly reduced. Therefore, the high boric acid corrosion rate shown in Figure 1 (b) can be explained as being related to the high phosphorus segregation in ferrite phases as a result of the bending process, as confirmed by the selective ferrite corrosion observed in Figure 3.

\section{CONCLUSIONS}

1) For the induction heat bent ASME SA335 Gr. P22 alloy steel pipe, every bent region exhibited a higher boric acid corrosion rate than that of the base metal. It is considered that the locally heated band induced the enrichment of phosphorus in the ferrite phase, and the enriched areas acted as initiation sites of corrosion in the boric acid solution, since a P-enriched 


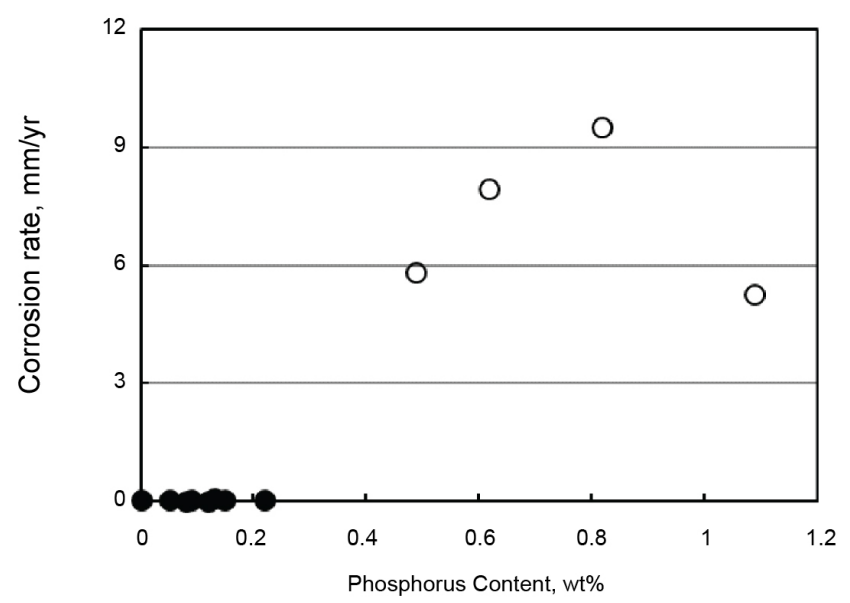

Fig. 8. Relationship between phosphorus content of the ferrite phase in the transition end region ( $\circ$ as-bent, $\bullet$ re-heat treated) and corrosion rate in deaerated $5,700 \mathrm{ppm}$ boric acid at $200{ }^{\circ} \mathrm{C}$

area may reduce the hydrogen evolution overpotential.

2) Re-heat treatment after the bending process enhanced corrosion resistance, and it was proved that its resistance was closely related to the degree of the phosphorus segregation in the ferrite phase. Therefore, re-heat treatment after bending is recommended.

\section{ACKNOWLEDGEMENT}

Research for this paper was supported by Sungil Co. Ltd. funded from the Korea Institute for the Advancement of Technology. Authors wish to thank both organizations.

\section{REFERENCES}

1. J. Niu, L. Qi, Y. Liu, L. Ma, Y. Feng, and J. Zhang, T. Nonferr. Metal. Soc. 19, 573 (2009).

2. F. W. Curtis, High-frequency Induction Heating, McGraw-Hill Book Company, Inc., New York (1950)

3. P. G. Simpson, Induction Heating Coil and System Design, McGraw-Hill Book Company, Inc., New York (1960).

4. PFI Standard ES-24, Pipe Bending Methods, Tolerances, Process and Materials Requirements, Pipe Fabrication Institute, Springdale, PA15144 (1987).

5. H. Blume, W. E. Speth, and K. Bredenbruch, Energy Development 12, 9 (1983).

6. K. H. Ryu, D. J. Kim, B. M. Kim, and D. J. Lee, Trans. Mater. Process. 10, 329 (2001).

7. T. Behne, International Association of Marine Investigators 1, 34 (1983).
8. K. T. Kim, Y. S. Kim, H. Y. Chang, Y. J. Oh, and G. H. Sung, Corros. Sci. Tech. 14, 47 (2015).

9. W. O'Keefe, Power 1, 74 (1977).

10. N. I. Kim, Y. S. Kim, K. S. Kim, H. Y. Chang, H. B. Park, and G. H. Sung, Corros. Sci. Tech. 14, 120 (2015).

11. S. Kuriyama and T. Aida, Proceedings of 4th International Conference on Technology of Plasticity, p. 464, Beijing (1993).

12. W. Zutang and H. Zhong, J. Mater. Process. Tech. 21, 275 (1990).

13. H. Zhong, J. Mater. Process. Tech. 102, 130 (2000).

14. H. Li, H. Yang, M. Zhan, and R. Gu, T. Nonferr. Metal. Soc. 16, 613 (2006).

15. G. J. Collie and I. Black, Journal of Materials: Design and Applications 223, 19 (2009).

16. ISO 15590-1, Petroleum and natural gas industries induction bends, fittings and flanges for pipeline transportation systems - Part 1: Induction bends, ISO ( 2001).

17. W. D. Callister, Jr. and D. G. Rethwisch, Fundamentals of Materials Science and Engineering an Integrated Approach, John Wiley \& Sons, Inc., NewYork (2003).

18. R. E. Reed-Hill, Physical Metallurgy Principles, 2nd ed., D. Van Nostrand Co., NewYork (1973).

19. M. Shin, Y. S. Kim, K. Kim, H. Y. Chang, H. B. Park, and G. Sung, Corros. Sci. Tech. 13, 87 (2014).

20. L. W. Ma, X. Wu, and K. Xia, Mater. Forum 32, 35 (2008).

21. N. Ozdemir, F. Sarsilmaz, and N. Orhan, J. Tribol. 130, 021602-1 (2008).

22. A. H. V. Pavan, K. S. N. Vikrant, G. Vimalan, and K. Singh, Case Studies in Engineering Failure Analysis 1, 120 (2013).

23. C. J. Czajkowski, Handbook of Case Histories in Failure Analysis, vol. 2, Materials Park, ASM International, $\mathrm{OH}$, USA, p. 163 (1993).

24. S. Sivaprasad, S. K. Narang, and R. Singh, Eng. Fail. Anal. 13, 867 (2006).

25. J. P. Slade and T. S. Gendron, Proceedings of the International Conference on Environmental Degradation of Materials in Nuclear Power Systems Water, p. 773, Warrendale, Pa. (2005).

26. EPRI-1000975, Boric Acid Corrosion Guidebook, Revision 1, EPRI (2011).

27. Yu. I. Babei, V. V. Zhitkov, Yu, I, Zvezdin, I. Yu. Liskevich, and A. A. Nazarov, Sov. Mater. Sci. 18, 135 (1982).

28. H. H. Uhlig and R. W. Revie, Corrosion and corrosion control, 3rd ed. John Wiley and Sons, N. Y. (1984).

29. Z. Foroulis and H. Uhlig, J. Electrochem. Soc. 112, 1177(1965).

30. ASME, ASME Boiler \& Pressure Vessel Section II-Part A, "Ferrous Materials Specifications (Beginning to SA-450)" (2011).

31. H. Ohtami and C. J. McMahon Jr., Acta Metall. 23, 377 (1974) 
32. J. Yu and C. J. McMahon Jr., Metall. Mater. Trans. A 11, 277 (1980).

33. R. D. K. Misra and T. V. Balasubramanian, Acta Metall. Mater. 38, 2357 (1990).

34. J. Perhacova, D. Grman, M. Svoboda, J. Patcheider, A.
Vyrostkova, and J. Janovec, Mater. Lett. 47, 44 (2001).

35. J. D. Demaree, G. S. Was, and N. R. Sorensen, Surf. Coat. Technol. 51, 6 (1992).

36. M. J. Kim, S. H. Lee, J. G. Kim and J. B. Yoon, Corrosion 66, 125005 (2010). 